Materials \& Design

Volume 103, 5 August 2016, Pages 32-39

http://dx.doi.org/10.1016/j.matdes.2016.04.061

http://www.sciencedirect.com/science/article/pii/S0264127516305354

\title{
Modification of Interactions in Polypropylene/Lignosulfonate blends
}

\author{
Brúnó Bozsódi ${ }^{1,2}$, Vivien Romhányi ${ }^{1,2}$, Piroska Pataki ${ }^{1,2}$, Dávid Kun ${ }^{1,2,{ }^{*}}$, Károly Renner $^{1,2}$ and \\ Béla Pukánszky ${ }^{1,2}$
}

${ }^{1}$ Laboratory of Plastics and Rubber Technology, Department of Physical Chemistry and Materials Science, Budapest University of Technology and Economics, H-1521 Budapest, P.O.Box 91, Hungary

${ }^{2}$ Institute of Materials and Environmental Chemistry, Research Centre for Natural Sciences, Hungarian Academy of Sciences, H-1519 Budapest, P.O. Box 286, Hungary

*Corresponding author: Phone: +36-1-463-4337, Fax: +36-1-463-3474, Email: kun.david@mail.bme.hu

Keywords: lignin blends, miscibility, compatibility, dispersed structure, local deformations, interfacial adhesion 


\section{Astract}

Polypropylene (PP)/lignin blends were prepared in a wide composition range $(0-70$ vol\%) from a PP homopolymer and two lignosulfonates of different compositions by homogenization in an internal mixer and compression molding. Thermodynamic considerations and dynamic mechanical analysis (DMTA) were used for the estimation of interactions and miscibility, while mechanical properties were characterized by tensile testing. Local deformations were followed by acoustic emission measurements, and structure was analyzed by scanning electron microscopy (SEM). The results showed that the structure of the blends form during processing by the breakup of large lignin particles which soften at the high temperature of processing. Weak interactions develop between PP and lignin, since lignin molecules interact with each other strongly and prevent the mixing of the two components. Dispersed structure forms in the entire composition range studied, co-continuous structure cannot develop at all. Interfacial adhesion can be improved through the addition of a maleic anhydride grafted polypropylene (MAPP) coupling agent. Depending on the strength of interfacial adhesion the blends fail either by debonding or the fracture of the lignin particles. Although coupling improves the strength of the blends, deformability is very small especially at larger lignin content hindering practical application. 


\section{Introduction}

After cellulose, lignin is the second most abundantly available material in nature [1]. It is a basic constituent of all lignocellulosic materials and industry produces it in increasing amounts as a side product of cellulose and bioethanol production [2]. The chemical structure and properties of lignin depend very much on the technology (e.g. Kraft, sulfite, organosolv, steam explosion process) used to extract it from plants and thus its application also depends somewhat on this process. Kraft lignin is mainly used to produce energy [3], while lignosulfonates are applied in various areas as additive for concrete [4], animal feed pelleting [5] and dust control [6], raw material for the production of certain chemicals [7-9], etc. Because of its quantity and being a side product, lignin is very cheap thus using it in any value added application would result in considerable economical gain. Blending with polymers could be a potential application and several attempts have been reported in the literature about the structure, interactions and properties of polymer/lignin blends [10-26].

Polyolefins, including polypropylene, are commodity polymers used in very large quantities in industrial practice. They are very cheap, but possess good, balanced properties resulting in a wide range of applications. Polypropylene can be further modified in various ways to extend its range of properties and applications. Its stiffness is increased by the incorporation of fillers or fibers [27], impact resistance by modifying it with elastomers [28], nucleation results in larger stiffness [29], but often also in good optical properties [30]. Combining PP with lignin might result in blends with an advantageous property combination at an acceptable price. The properties of blends depend on their structure, which, on the other hand, is determined by the interaction of the components. Complete miscibility usually results in properties in between those of the components, while the characteristics of immiscible blends 
often go through a minimum [31], although heterogeneous structure may result in increased fracture resistance [32]. Obviously the interaction of the components is a key factor determining the properties of blends; weak interactions result in immiscibility and poor properties. Lignin is a very polar, while polyolefins are apolar polymers, thus the strong interactions developing among lignin molecules are expected to result in very poor miscibility.

In spite of the prediction stated above, a wide range of opinions have been published about the miscibility or compatibility of lignin and polyolefins. Some authors found significantly different compatibility in high density and low density polyethylene (LDPE) [33], which is difficult to understand in view of the very similar chemical structures and interactions developing in the two kinds of blends. Although Doherty et al. [2] explained the difference with the possible unfavorable entropic effect of short chain branches, the explanation is very difficult to believe. Kadla and Kubo [34] found that PP and Kraft lignin formed immiscible blends as no specific interactions developed between the components. Pouteau et al. [35] observed poor compatibility between LDPE, PP and unmodified Kraft lignin. The authors also blended PP with different molecular weight fractions of lignin and claimed a significant improvement of compatibility as the molecular weight of lignin decreased. Good compatibility was found between PP and organosolv as well as prehydrolysis lignin by Košiková [36], while Jeong et al. [37] claimed complete miscibility of lignin with several polymers including LDPE, PP, polystyrene and poly(ethylene terephthalate). Unfortunately, these claims were supported by very little experimental evidence. In spite of the claims about good compatibility and even miscibility, properties were shown to deteriorate upon blending lignin with most polymers including polyolefins. Although stiffness usually increases in larger or smaller extent [37-45], tensile strength and deformability decrease in most cases [37,39-50] indicating poor 
interactions and the development of a heterogeneous structure. The inferior compatibility of lignin with polyolefins is shown also by the numerous attempts to improve interactions and miscibility in such blends. Lignin has been modified by stearoyl chloride [51], grafted with ethylene monomers [52], esterified with phthalic [44] and maleic anhydride [45], alkylated by dichloroethane [45] and dodecane bromide [50], or compatibilized by a third component. Ethylene-vinyl acetate copolymer $[39,40,43,52]$ or maleated polyethylene $[43,44]$ was added to the blend to modify structure and improve properties in the latter case. Some of these modifications were claimed to improve blend properties significantly and make possible the production of films for practical applications $[39,40,43,44,51,53]$.

In spite of these attempts and claims, considerable controversy surrounds the preparation of polymer/lignin blends, the interactions developing among the components, as well as the resulting structure and properties. Since polypropylene is a cheap commodity polymer available in large quantities, it seemed to be obvious to use it as a matrix for lignin blends. In view of the controversies mentioned above the goal of our study was to prepare $\mathrm{PP} /$ lignin blends in a wide composition range, estimate interactions in them, modify those interactions by coupling, if possible, and determine the resulting structure and properties. We also intended to study the deformation and failure mechanism of the blends in order to obtain further information about structure and interactions, and draw conclusion about the possible use of these materials in practical applications. 


\section{Experimental}

The polypropylene used as matrix in the experiments was the Tipplen H 649 FH grade homopolymer supplied by Tisza Chemical Works Ltd., Hungary. It has an MFR of $2.5 \mathrm{~g} / 10$ min at $230{ }^{\circ} \mathrm{C}$ and $2.16 \mathrm{~kg}$ and a nominal density of $0.9 \mathrm{~g} / \mathrm{cm}^{3}$. The two lignin samples used in the experiments were kindly supplied by Burgo Cartiere SpA, Italy. The Bretax C grade is the primary by-product of cellulose production and the counter ion of the sulfonate groups is calcium. The Bretax SRO2 is a modified product, in which calcium ions are exchanged to sodium ions and a significant part of its sugar content is oxidized. Both grades have small molecular weight (1400-2400 g/mol), and they contain various amounts of inorganic salts and sugar. Whenever in further discussion lignin is mentioned, we always mean lignosulfonate under this term. Interactions were modified by the addition of MAPP coupling agents. The Polybond 3200 grade (MA content: $1 \mathrm{wt} \%$, MFR: $106 \mathrm{~g} / 10 \mathrm{~min}$ at $190{ }^{\circ} \mathrm{C}$ and $2.16 \mathrm{~kg}, \mathrm{M}_{\mathrm{n}}$ : $33000 \mathrm{~g} / \mathrm{mol}$ ) produced by Chemtura, USA, was used together with the Bretax C lignin, while the Orevac CA100 grade of Arkema, France (MA content: 1 wt\%, MFR: 112 g/10 min at 190 ${ }^{\circ} \mathrm{C}$ and $2.16 \mathrm{~kg}, \mathrm{M}_{\mathrm{n}}: 25000 \mathrm{~g} / \mathrm{mol}$ ) was applied in blends containing the SRO2 grade. The amount of lignin increased from 0 to $70 \mathrm{vol} \%$ in $10 \mathrm{vol} \%$ steps in the blends, while the amount of MAPP was always $20 \%$ related to the quantity of lignin added.

The components were homogenized in a Brabender W 50 EHT internal mixer at $190^{\circ} \mathrm{C}$ set temperature, $42 \mathrm{~cm}^{3}$ charge volume, $42 \mathrm{rpm}$ and $10 \mathrm{~min}$ mixing time after the addition of lignin. Plates of $1 \mathrm{~mm}$ thickness were compression molded from the homogenized blends at $190{ }^{\circ} \mathrm{C}$ using a Fontijne SRA 100 machine. After one week storage at room temperature, tensile bars were machined from the plates for further testing. 
Dynamic mechanical thermal analysis (DMTA) was carried out on specimens with 60 x 5 x $1 \mathrm{~mm}$ dimensions between -50 and $+200{ }^{\circ} \mathrm{C}$ at $1 \mathrm{~Hz}$ frequency, $10 \mu \mathrm{m}$ amplitude and 2 ${ }^{\circ} \mathrm{C} /$ min heating rate. Mechanical properties were further characterized by tensile testing using an Instron 5566 universal testing machine. Gauge length was $80 \mathrm{~mm}$ and the test was done at $10 \mathrm{~mm} / \mathrm{min}$ cross-head speed. Local deformation processes were followed by acoustic emission testing. The signals were detected with a Sensophone AED-40 type equipment at $20 \mathrm{~dB}$ threshold level. The structure of the blends was analyzed by scanning electron microscopy (SEM) using a Jeol JSM 6380 LA apparatus. Thin slices were cut from the $1 \mathrm{~mm}$ thick plates with a Leica EM UC6 microtome at $-60{ }^{\circ} \mathrm{C}$ and then the lignosulfonate was dissolved from the slices by soaking them in distilled water for 24 hours at ambient temperature. Micrographs were recorded on fracture surfaces created during tensile testing in order to obtain information about local deformation and failure processes. 


\section{Results and discussion}

The results are presented in several sections. First the crucial issue of interactions is discussed, followed by the presentation of the resulting structure. Deformation and failure mechanism as well as the composition dependence of blend properties are analyzed in the next sections and then general correlations and consequences for practice are discussed in the end.

\subsection{Interactions}

As mentioned in the introductory section, conclusions published in the literature about the compatibility of polyolefins and lignin contradict each other seriously. Considering the structure of lignin that contains a number of aromatic rings and several functional groups including ionic, aliphatic and phenolic hydroxyl as well as methoxy and acid groups, one would expect the development of very strong interactions among lignin molecules. The existence of these interactions is supported by the fact that lignin in itself cannot be melted and processed by any processing technology. Polypropylene is very apolar containing only carbon and hydrogen atoms and capable of forming only very weak dispersion interactions. As a consequence, any kind of miscibility or compatibility between lignin and PP would be quite surprising.

Interactions and miscibility can be estimated in various ways in polymer blends. The simplest is the determination of solubility parameters. The value of $33.1 \mathrm{MPa}^{1 / 2}$ derived from solubility tests was published for calcium lignosulfonate by Myrvold [54]. The solubility parameter of polypropylene was calculated from Hoy's group contributions yielding a value of 16.0 $\mathrm{MPa}^{1 / 2}$. The very large difference between the two quantities predicts complete immiscibility for the two materials, i.e. lignin and PP. The Flory-Huggins interaction parameter 
can be approximately calculated from solubility parameters [55] and a value of 5.8 was obtained, which is also very large and predicts the lack of compatibility. In view of these calculations the claim of partial or even complete miscibility [37] of lignin and polyolefins is difficult to understand.

Another way to estimate miscibility is the determination of the glass transition temperature $\left(\mathrm{T}_{\mathrm{g}}\right)$ of the components. Usually a single transition temperature is detected in miscible blends, while two $\mathrm{T}_{\mathrm{g}}$ 's corresponding to that of the two components is expected to appear at complete immiscibility [4]. The temperature dependence of the loss tangent of a blend series is presented in Fig. 1. Storage and loss moduli convey the same message thus we refrain from their presentation here. Similarly, the temperature dependence of $\operatorname{tg} \delta$ as well as the effect of composition on it was very similar also for the other three series of PP/lignin blends. Three transitions can be detected on the traces. The relaxation transition of the amorphous phase of PP appears approximately at $2{ }^{\circ} \mathrm{C}$. The other two transition temperatures observed at around 70 and $120^{\circ} \mathrm{C}$ might be assigned to the relaxation of the rigid amorphous phase of PP and to that of lignin, but the assignment needs further analysis and verification. 


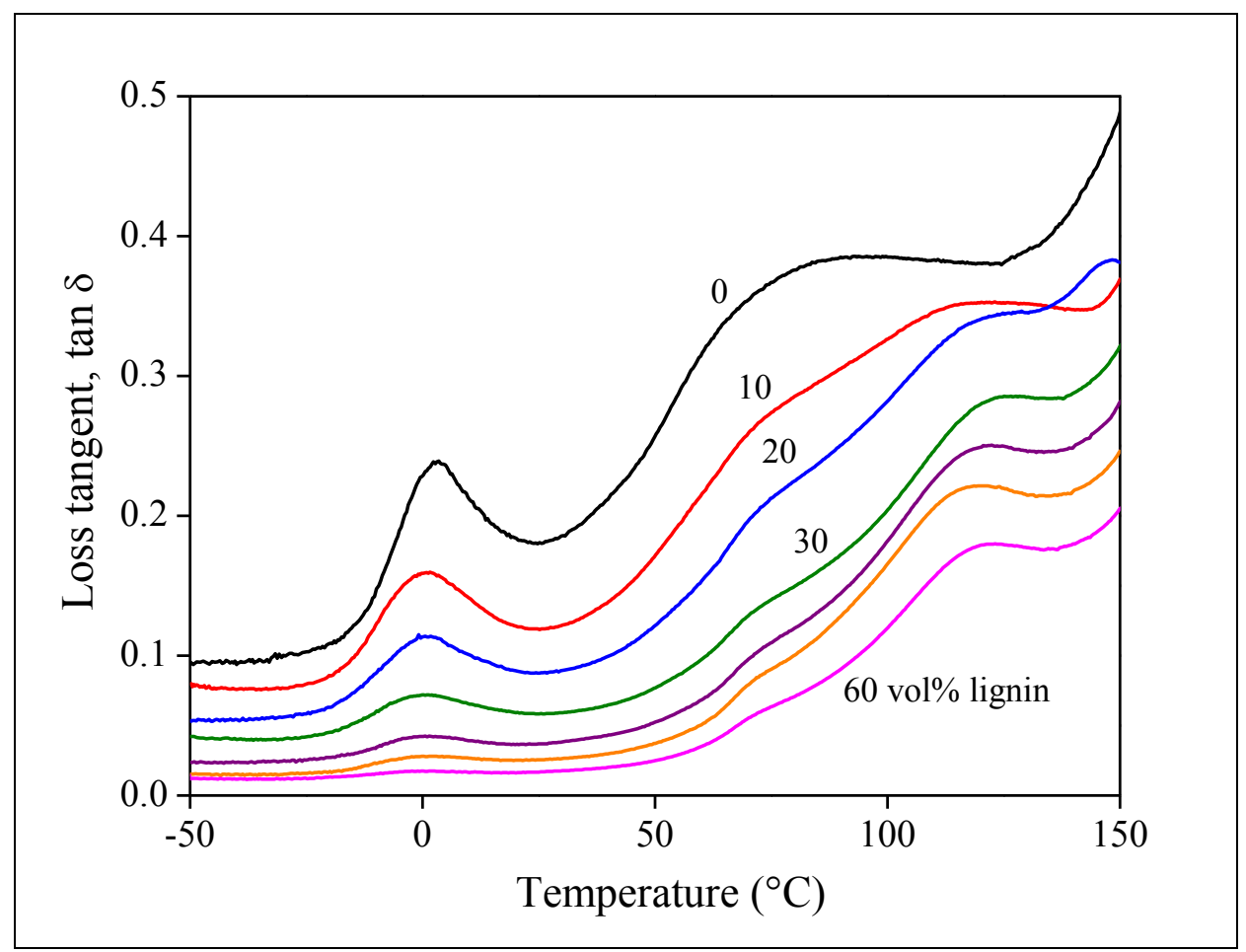

Figure 1. Temperature dependence of the loss tangent $(\operatorname{tg} \delta)$ of $\mathrm{PP} /$ lignosulfonate (Bretax C) samples containing a MAPP coupling agent (Polybond 3200). Effect of composition; lignin content increases from top to bottom.

However, the quantitative analysis of all transition temperatures indicates that they are completely independent of composition which clearly proves the lack of strong interactions and miscibility. An example is shown in Fig. 2 in which the glass transition temperature of the amorphous phase of PP is plotted against the lignin content of the blends. The $\mathrm{T}_{\mathrm{g}}$ of PP seems to be completely independent of the type of lignin and MAPP used as well as the amount of lignin in the blend. Contrary to some claims in the literature, all considerations and results indicate the complete immiscibility of lignin and PP. 


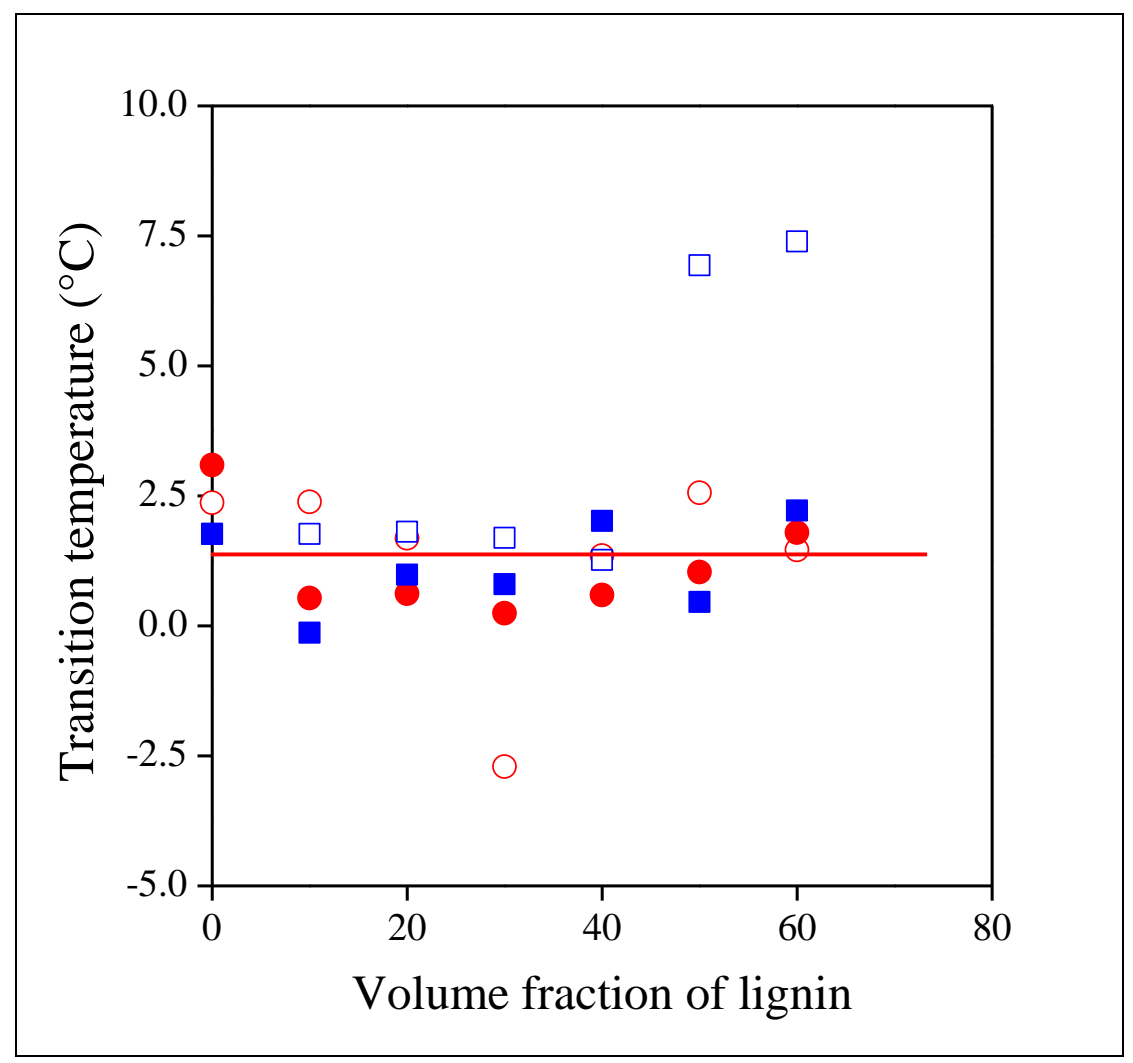

Figure 2. Independence of the glass transition temperature of the PP matrix of lignin type, content and coupling. Symbols: $(\bigcirc)$ Bretax C, ( $)$ Bretax C/MAPP, $(\square)$ Bretax SRO2, (ם) Bretax SRO2/MAPP.

\subsection{Structure}

The structure of miscible blends is homogeneous, phase separation does not take place in them. On the other hand, two-phase structure forms in immiscible blends, usually one of the polymers is dispersed in the other in the form of droplets at the two sides of the composition range, while a co-continuous structure forms in between. The width of this latter depends on the interaction of the components, it becomes wider at stronger interactions. The structure of all PP/lignin blends was heterogeneous, lignin droplets dispersed in the PP matrix at all 
compositions, even at $70 \mathrm{vol} \%$ lignin content. The original lignin particles are quite large as shown by Fig. 3a. The average particle size was around $80 \mu \mathrm{m}$ for both lignin grades. The particles break up during processing, their average size decreases considerably. A typical micrograph is presented in Fig. $3 \mathbf{b}$ for the PP/SRO2 blend, while the effect of coupling is shown in Fig. 3c. Average particle size is in the range of $10 \mu \mathrm{m}$ in the former and $1 \mu \mathrm{m}$ in the second case. One may consider changing particle size as a sign of miscibility, but we assume that lignin softens at the relatively high temperature of processing and breaks up during mixing. The final size of the particles depend on mixing conditions, i.e. shear, and on interactions. The coupling agent stabilizes smaller particles and prevents their coalescence.

The lack of miscibility is demonstrated well by Fig. 4 showing the composition dependence of particle size for the two series prepared with the SRO2 lignin. Particle size does not change or increases slightly with increasing lignin content in both series. Particle break up and coalescence compete during mixing, the second becoming more important with increasing lignin content. This latter effect leads to the development of a co-continuous structure in most polymer blends. However, the effect is rather weak in the PP/lignin blends, and even more importantly, co-continuous structure does not form at any compositions indicating again the development of weak interactions and the lack of miscibility. Coupling is a surface related effect and does not change the structure of the blends principally, but modifies only particle size. The study of blend structure indicates again the poor miscibility of the components. 


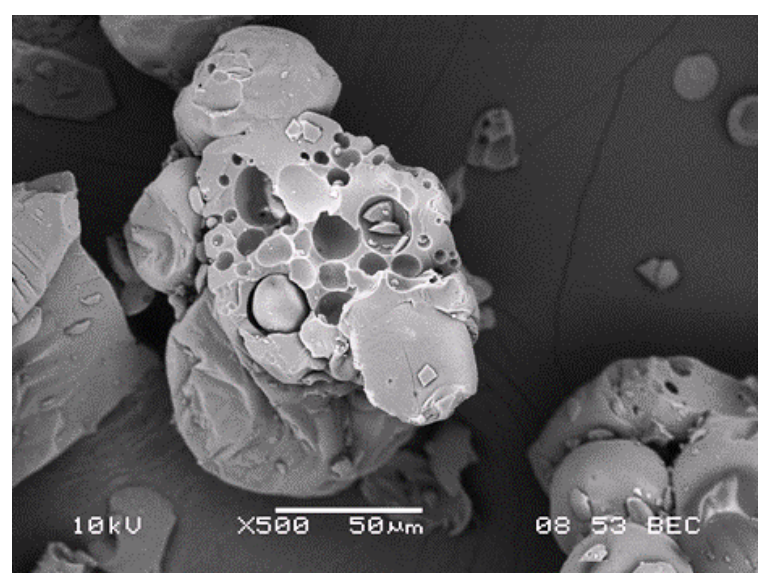

a)

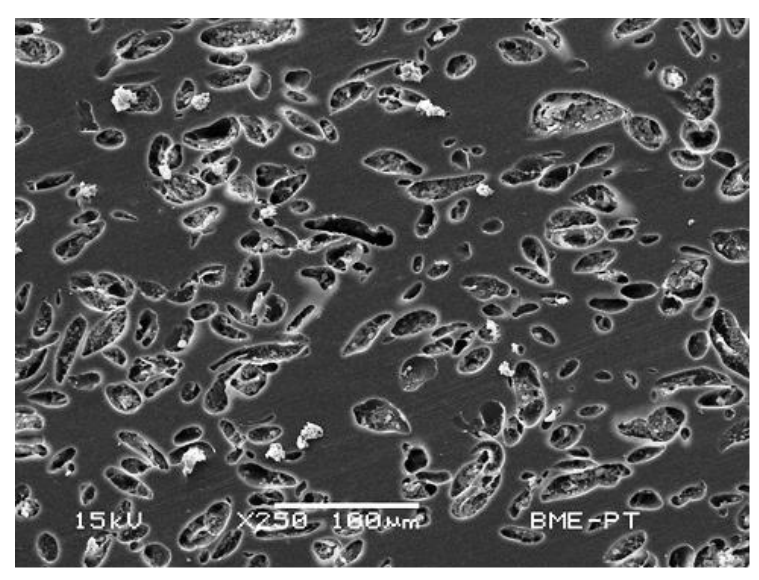

b)

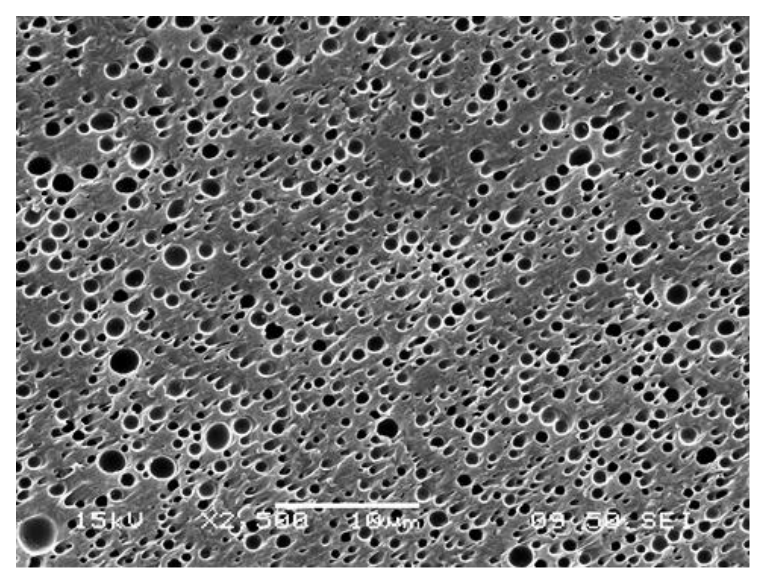

c)

Figure 3. Particle size and size distribution of the SRO2 lignin dispersed in PP; a) original lignin particles, b) 30 vol\% lignin, no coupling, c) 30 vol $\%$ lignin, MAPP. 


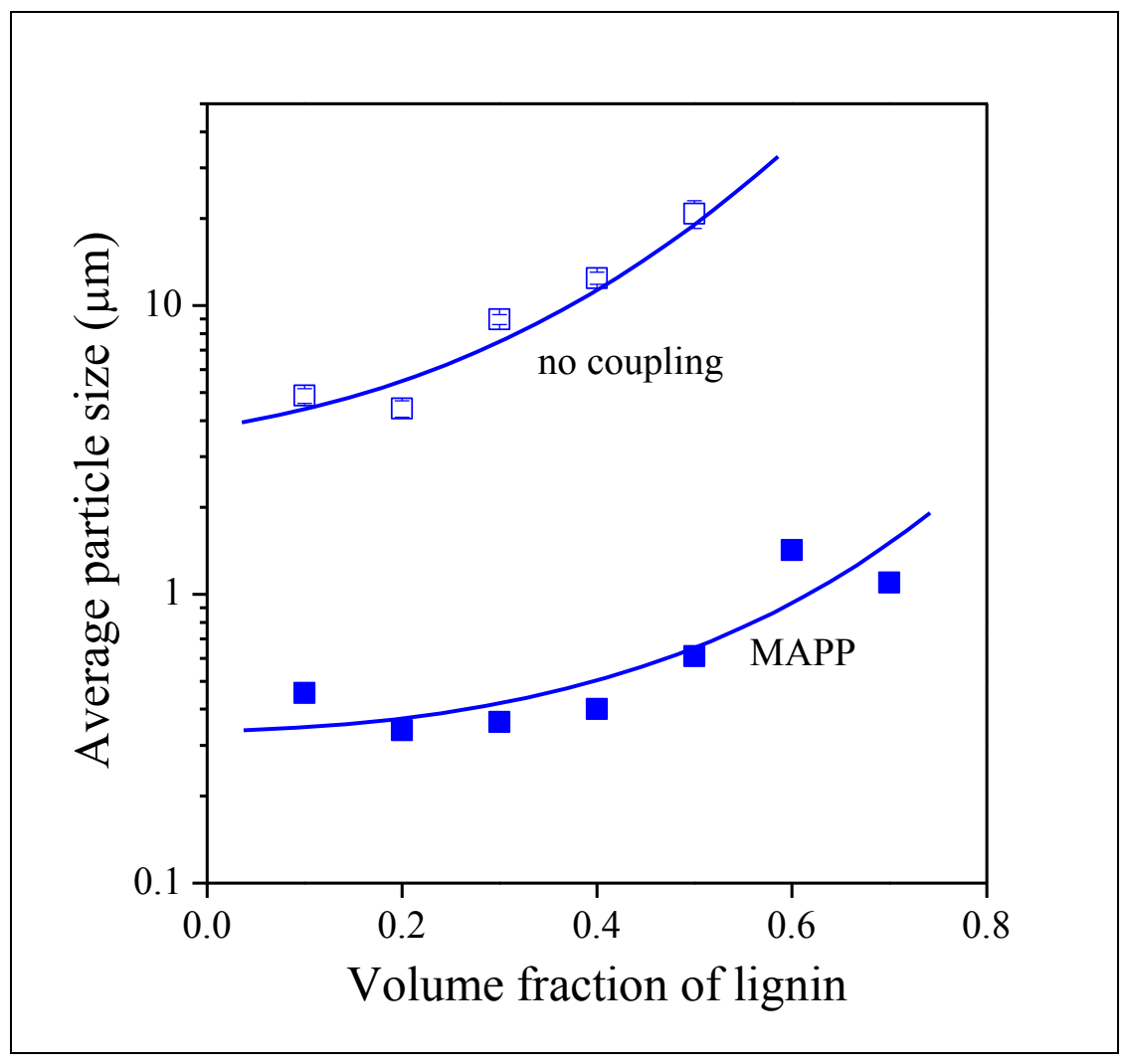

Figure 4. Effect of lignin content on the average particle size of the SRO2 lignin dispersed in PP; ( $\square$ ) no coupling, ( $\mathbf{\square})$ MAPP.

\subsection{Failure mechanism}

The study of deformation and failure mechanism might offer further information about interactions, but also about the performance of the blends. Local deformations occurring around inclusions generate elastic waves which can be detected by piezoelectric sensors. The results of such a test is shown in Fig. 5 for the PP blend containing 20 vol\% of the Bretax C lignin. Individual events indicated by small circles form two groups; one large group at small deformations and another, sparser one throughout the rest of the test. The stress vs. deformation trace is also included as reference. Further information can be deduced from the test if we also plot the cumulative number of signals as a function of deformation. The trace clearly shows 
that the majority of the signals develop at small deformations, at around $1 \%$. Such traces tending towards saturation are usually detected when debonding, i.e. the separation of the inclusions from the matrix at the interface, is the dominating deformation process. The slow increase of the number of signals with increasing deformation indicates the occurrence of another process, e.g. the fracture of the particles.

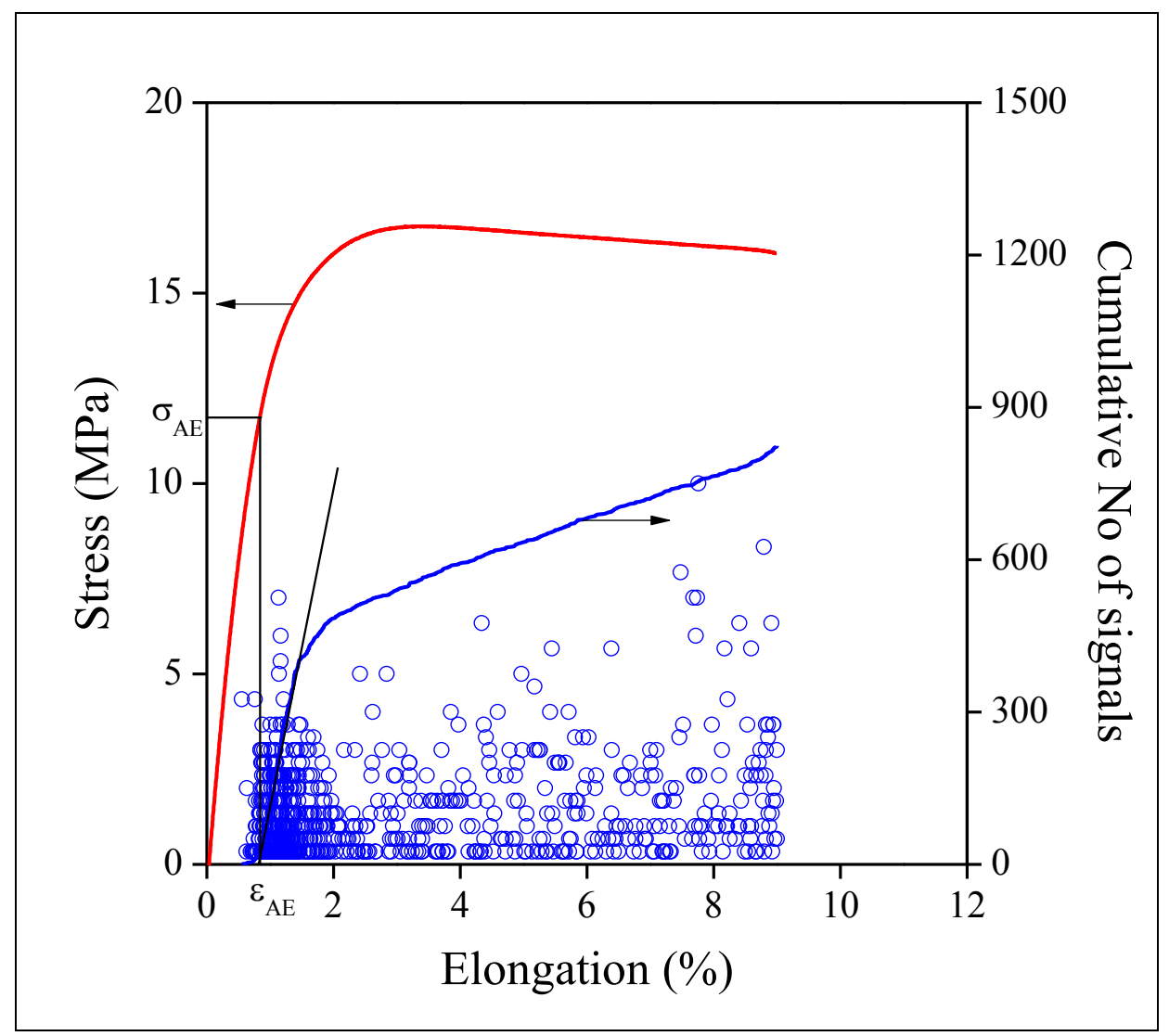

Figure 5. Acoustic emission testing of a PP/Bretax C blend; lignin content: $20 \mathrm{vol} \%$, no coupling. Stress vs. elongation trace is plotted as reference. $\bigcirc$ individual signals, cumulative number of signals. 
Coupling changes both the evolution of the signals and the shape of the cumulative number of signal trace quite considerably (Fig. 6). The number of signals increases about ten times, the main deformation process is initiated at larger deformation and the number of events increases continuously until the end of the test. These features indicate improved interfacial adhesion and particle fracture as the dominating deformation process. This also confirms that coupling is a surface related process in this case and does not change the miscibility of the components.

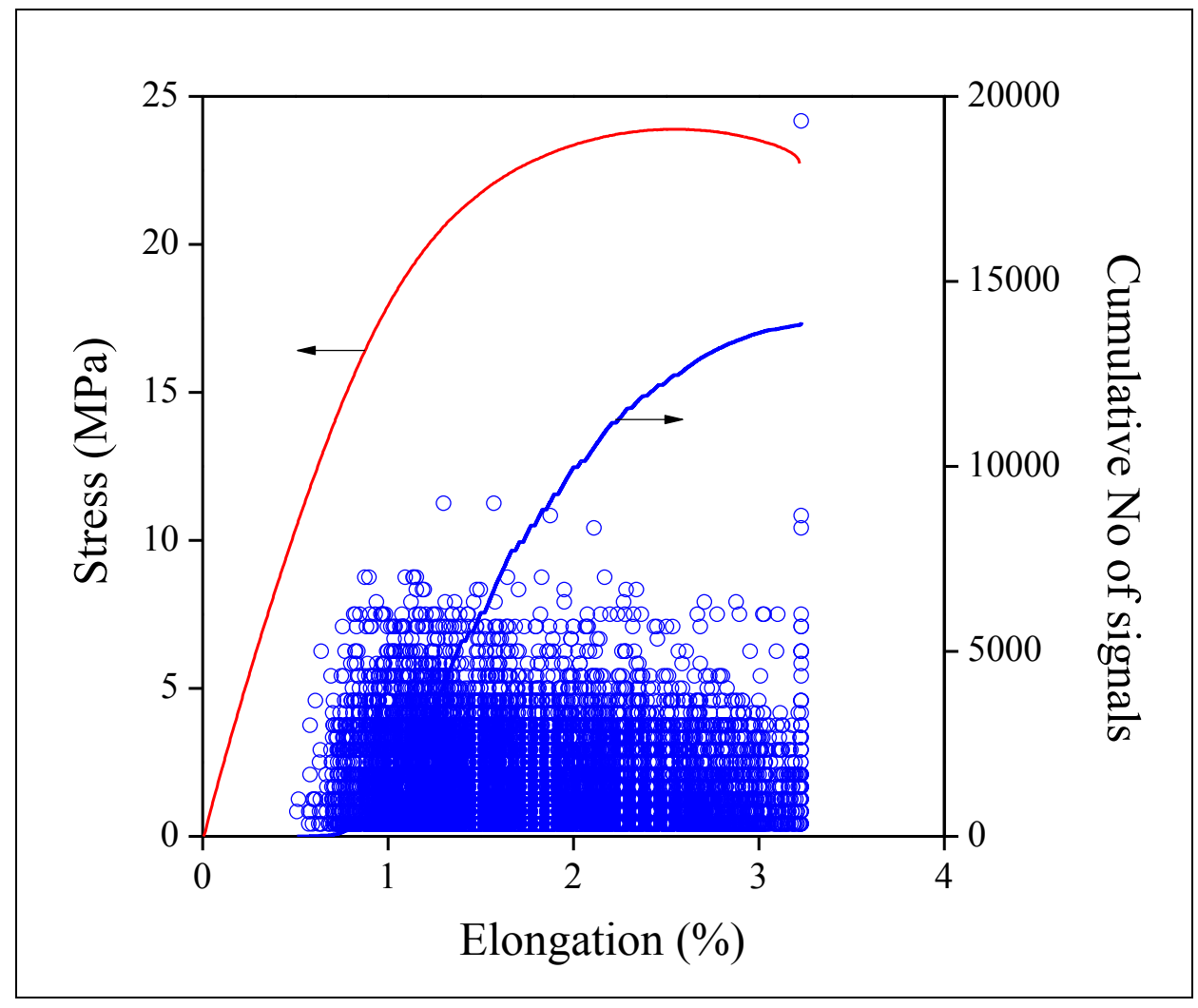

Figure 6. Effect of coupling on the acoustic emission pattern of PP/20 vol\% Bretax C blend. MAPP: Polybond 3200. Symbols are the same as in Fig. 5. 
The conclusions about the deformation mechanism of the blends are based on previous experience [56-59] and on indirect evidence related to the number of signals and the shape of the traces. SEM might supply further evidence about the mechanism of deformation and failure. The micrograph recorded on the fracture surface of a specimen containing $20 \mathrm{vol} \%$ of the Bretax $\mathrm{C}$ lignin is presented in Fig. 7a. The debonding of particles of all sizes and the fracture of large particles are clearly seen in the micrograph, both confirming our tentative explanation presented above. A much more homogeneous and featureless picture is offered by the micrograph taken from the blend which contained the MAPP coupling agent (Fig. 7b). Much less debonding is seen in the micrograph, less shear deformation than in Fig. 7a and less well defined interfaces. The fracture of larger particles can be detected, but more difficult to observe than previously, because of the lack of clear interfaces. Nevertheless, the micrographs clearly prove that debonding and particle fracture are the two main deformation processes occurring in PP/lignin blends, the first dominating in the blends without coupling, while the second in the case of strong interfacial adhesion. 


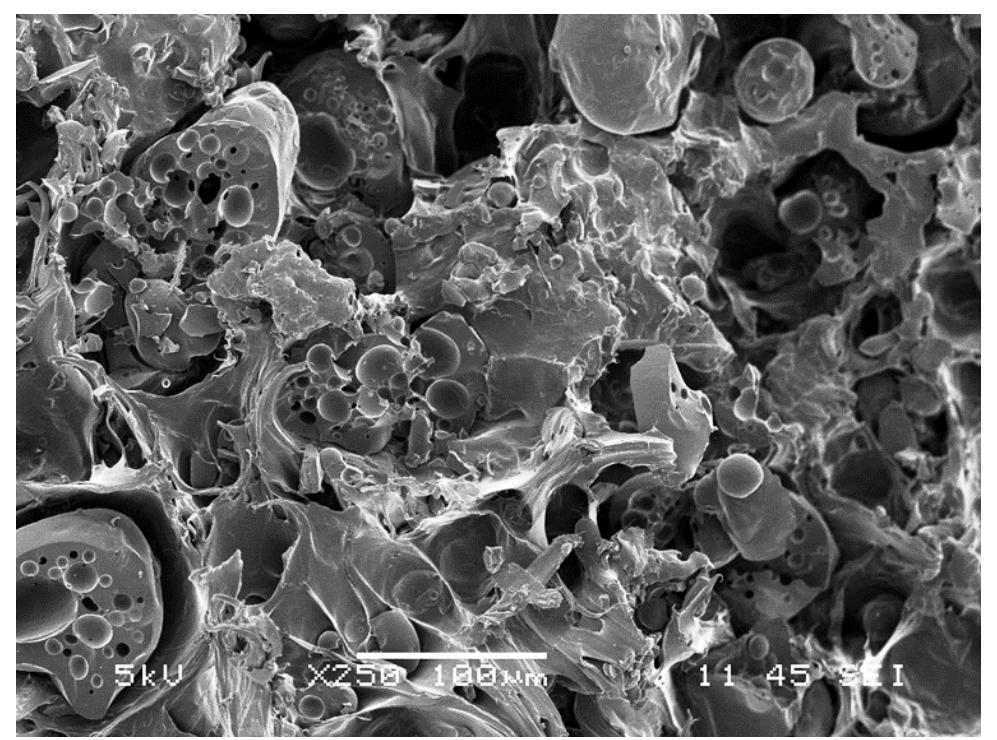

a)

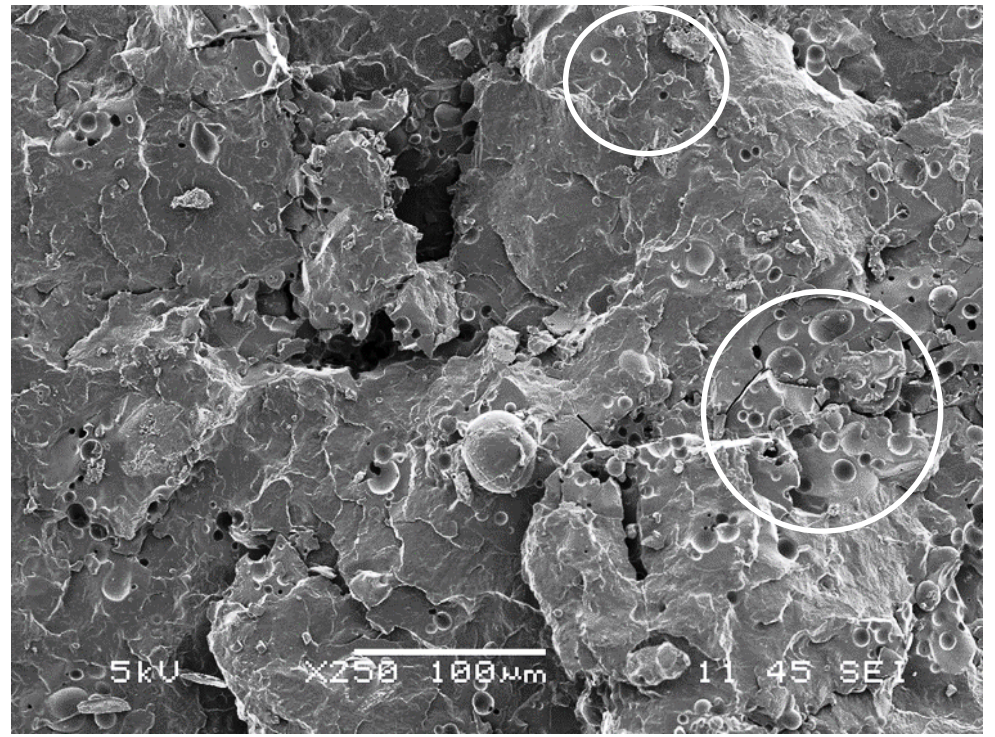

b)

Figure 7. Deformation and failure mechanism of PP/lignin blends. Lignin: 20 vol\% Bretax C. a) no coupling; debonding, shear yielding and particle fracture; b) MAPP; limited debonding, and particle fracture. 


\subsection{Properties}

Similarly to miscibility and interactions, the information published on the properties of polyolefin/lignin blends is quite contradictory. Modulus increased in most cases [37-45], but occasionally a decrease was observed with increasing lignin content $[50,53]$, which seems to be rather strange. On the other hand, strength and deformability mostly decreased [37,39-50], but larger strength and elongation-at-break than those of the matrix polymer were also observed occasionally $[39,40,43]$. Since properties depend on structure and interactions, the contradictory information indicates the improper characterization of these factors. The particle size of the dispersed phase, for example, was never given in the papers cited above.

The stiffness of two sets of blends is plotted against lignin content in Fig. 8. Young's modulus increases with increasing lignin content as expected. The stiff molecules and strong interactions of lignin results in a very stiff material which should reinforce PP. The stiffness of the blend not containing the coupling agent is smaller than that of the other series, the one prepared with MAPP. The difference might seem surprising at the first glance, since stiffness usually depends mainly on the volume fraction of the second component and not on particle size or interaction. However, the very large lignin particles in the former set of blends debond very easily at small deformations yielding a material with voids and small modulus. This result further confirms that without coupling or other modification the interaction between lignin and $\mathrm{PP}$ is very poor. 


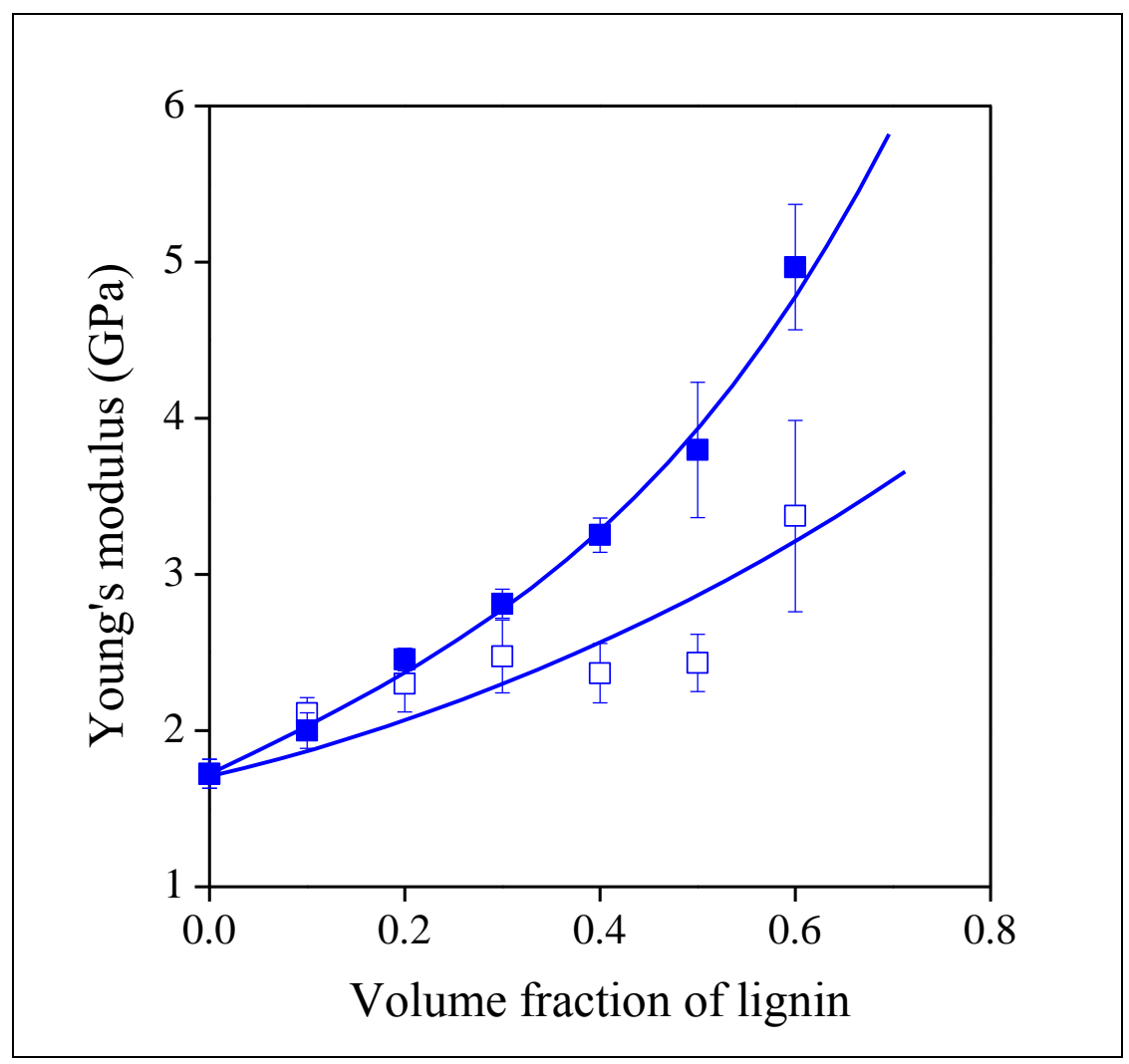

Figure 8. Effect of lignin content on the stiffness of PP/SRO2 blends; ( $\square$ ) no coupling, MAPP.

Properties measured at larger deformations are much more sensitive to interactions than modulus. This statement is strongly corroborated by Fig. 9 in which the tensile strength of the same two sets of blends is plotted against lignin content as in the previous figure. Tensile strength decreases with increasing lignin content in the absence of coupling, while it increases when MAPP is also added. This results confirms the conclusion drawn in section 3.2 claiming that debonding is the dominating local deformation process in the former case, while the fracture of the particles in the second. This latter process becomes less probable and more difficult with decreasing particle size because of the decreasing number of flaws in small 
particles. Although both modulus and strength can be improved by the application of the MAPP coupling agent, unfortunately deformability decreases invariably either with or without coupling. The elongation-at-break values of the blends are plotted against lignin content in Fig. 10 showing very small, around $1 \%$ deformability at large lignin loadings. The results clearly show that stiff and fragile materials are obtained at large lignin contents, which might limit their final application.

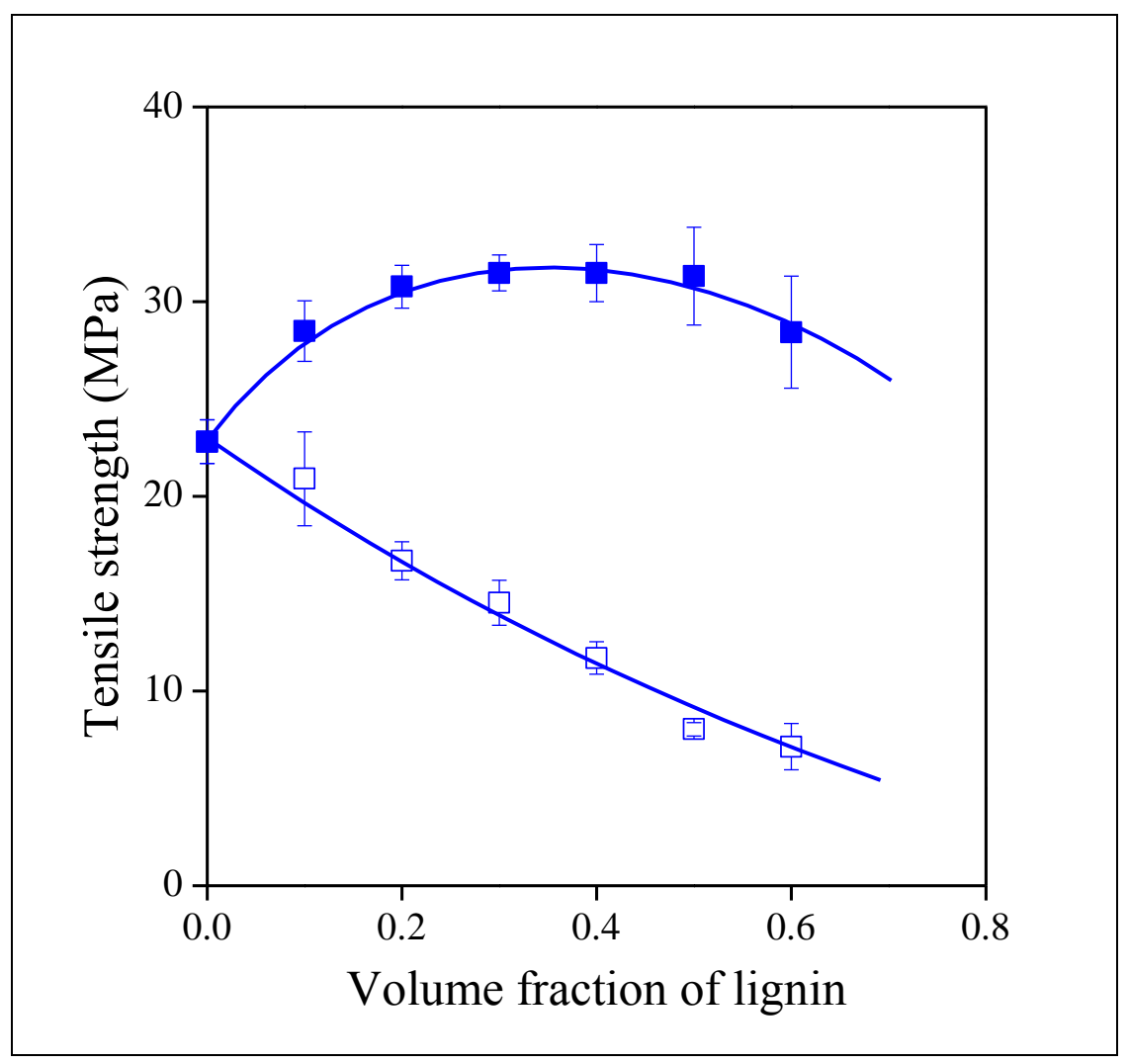

Figure 9. Tensile strength of $\mathrm{PP} / \mathrm{Bretax} \mathrm{SRO} 2$ blends plotted as a function of lignin content; ( $\square$ ) no coupling, ( $\square$ ) MAPP. 


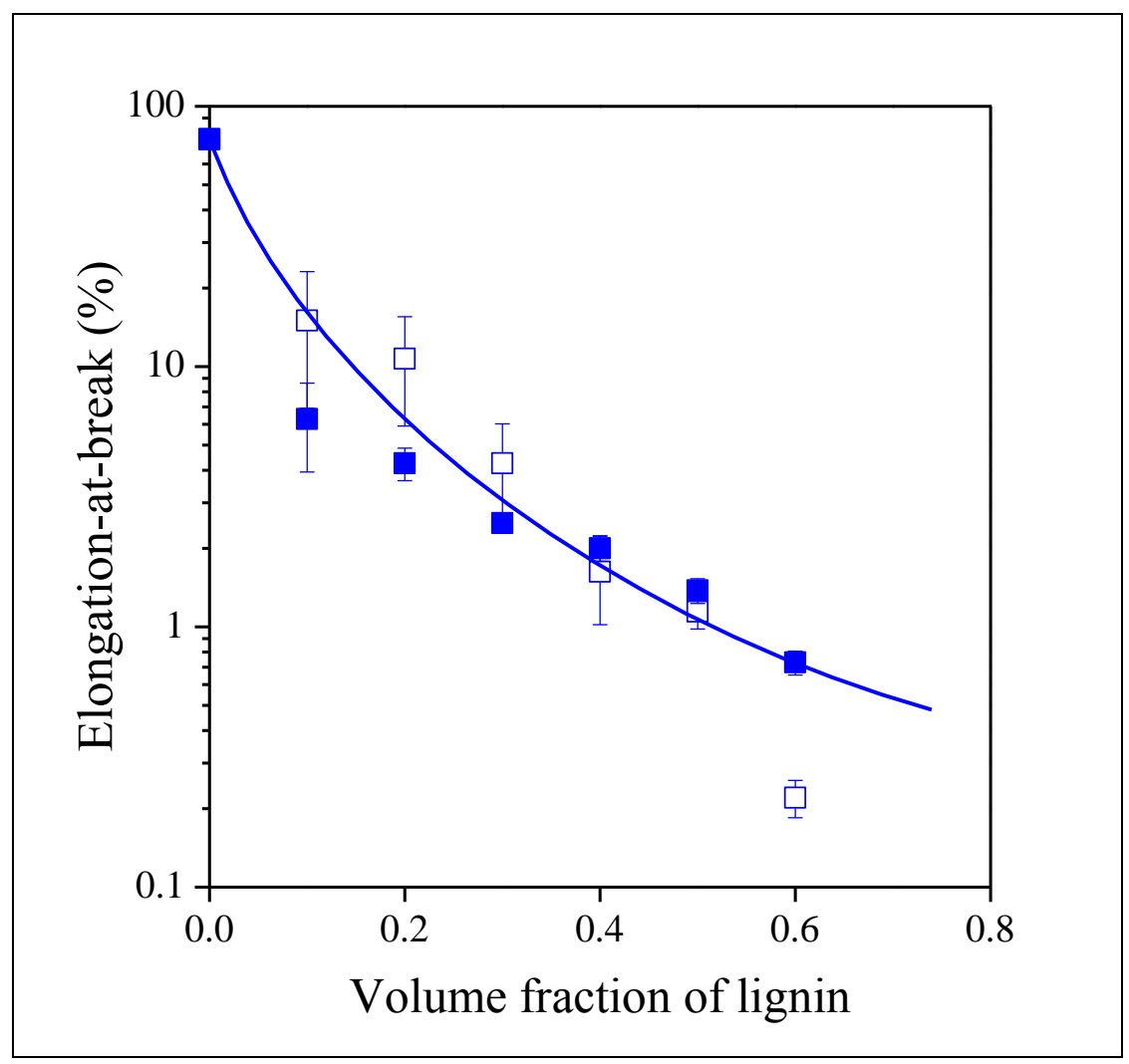

Figure 10. Dependence of deformability of PP/SRO2 blends on lignin content; ( $\square$ ) no coupling, ( $\square$ ) MAPP.

The measurement of the composition dependence of mechanical properties offers also the possibility to estimate interactions in particulate filled polymers and blends. The composition dependence of tensile strength can be expressed with the correlation $[60,61]$

$$
\sigma_{T}=\sigma_{T 0} \lambda^{n} \frac{1-\varphi}{1+2.5 \varphi} \exp (B \varphi)
$$

where $\sigma_{T}$ and $\sigma_{T 0}$ are the true tensile strength $\left(\sigma_{T}=\sigma \lambda\right.$ and $\lambda=L / L_{0}$, where $L$ is the ultimate and the $L_{0}$ initial gauge length of the specimen) of the composite and the matrix, respectively, 
$n$ is a parameter taking into account strain hardening, $\varphi$ is the volume fraction of the dispersed phase and $B$ is related to its relative load-bearing capacity, i.e. to the extent of reinforcement, which, among other factors, depends also on interfacial adhesion. If we transform Eq. 1 into a linear form (Eq. 2)

$$
\ln \sigma_{\text {Tred }}=\ln \left(\sigma_{T} \frac{1+2.5 \varphi}{1-\varphi} \frac{1}{\lambda^{n}}\right)=\ln \sigma_{T 0}+B \varphi
$$

and plot the natural logarithm of reduced tensile strength $\left(\sigma_{\text {Tred }}\right)$ against the volume fraction of the dispersed phase, we should obtain a straight line, the slope of which is proportional to the load-bearing capacity of the reinforcement, and under certain conditions to the strength of interaction. The tensile strength of two of the blend series is plotted in this way in Fig. 11. Both correlations are linear indeed with very different slopes showing dissimilar interfacial adhesion in the two cases, i.e. in the presence or absence of the MAPP coupling agent. We should like to remind the reader here to the fact that the value of $B$ is 0 at zero interaction and $B=1$ obtained for the PP/lignin blend is rather small, since values larger than 10 can be also obtained in the case of strong reinforcement $[62,63]$. Quantities characterizing the extent of reinforcement are collected in Table 1 for all four series. The results indicate that interfacial adhesion is the main factor determining reinforcement and the somewhat smaller $B$ value obtained for $\mathrm{PP} / \mathrm{Bretax} \mathrm{C}$ blends in the presence of coupling indicates somewhat different properties for this lignin (larger particles, smaller inherent strength) than for SRO2. 


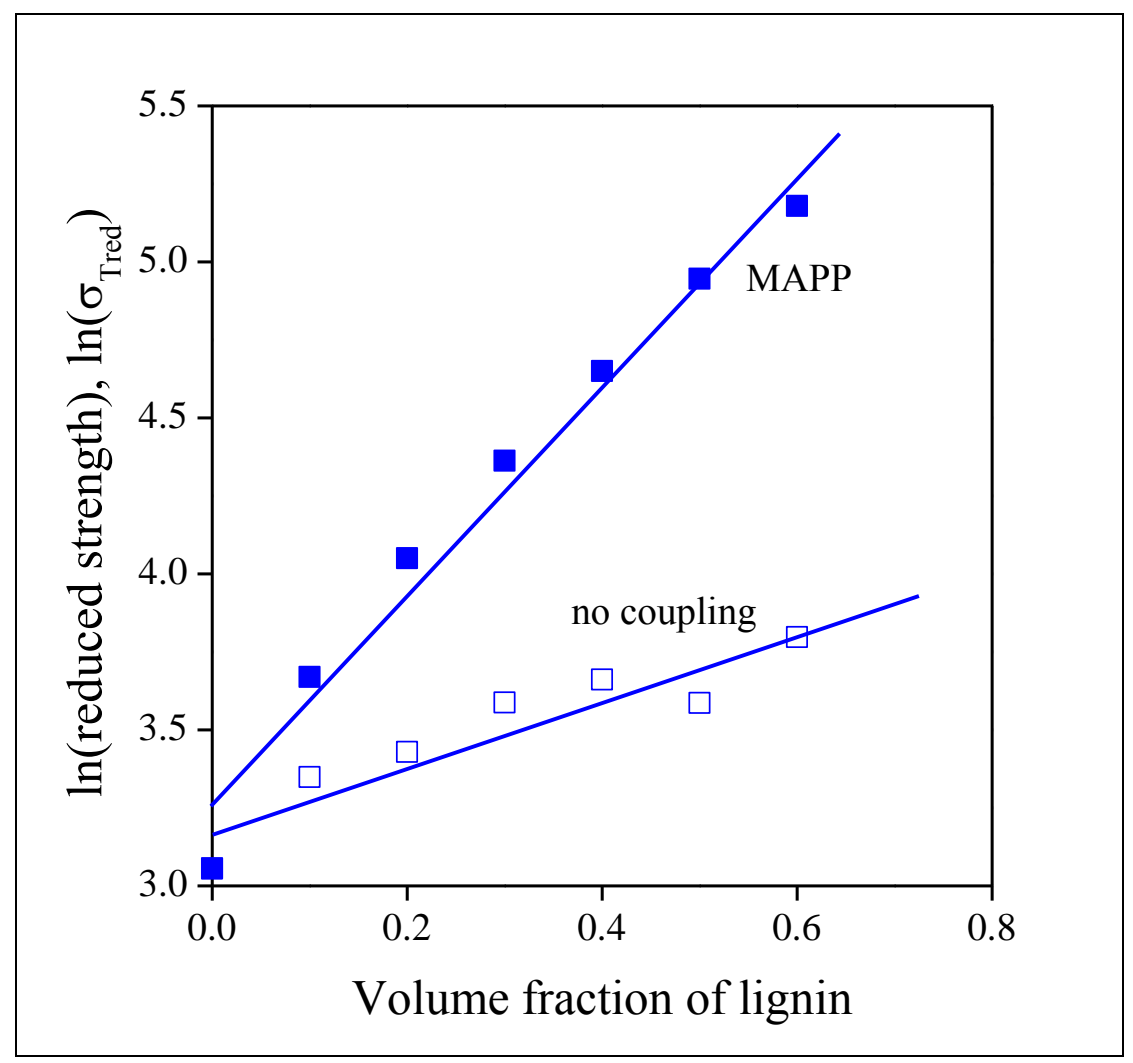

Figure 11. Reduced tensile strength of PP/Bretax SRO2 blends plotted against lignin content in the form of Eq. 2. Effect of coupling on reinforcement. ( $\square$ ) no coupling, (घ) MAPP.

Table 1. Reinforcing effect of lignin in PP; effect of lignin type and coupling

\begin{tabular}{|c|c|c|c|c|c|}
\hline \multirow[t]{2}{*}{ Lignin } & \multirow[t]{2}{*}{ Coupling } & \multicolumn{2}{|c|}{$\sigma_{T 0}(\mathrm{MPa})$} & \multirow[t]{2}{*}{$B$} & \multirow[t]{2}{*}{$\mathrm{R}^{2 \mathrm{~b}}$} \\
\hline & & measured & calculated $^{\mathrm{a}}$ & & \\
\hline \multirow{2}{*}{ Bretax C } & - & \multirow{2}{*}{$21.7 \pm 1.6$} & 25.7 & 1.13 & 0.9287 \\
\hline & MAPP & & 26.5 & 2.62 & 0.9406 \\
\hline \multirow{2}{*}{ Bretax SRO2 } & - & \multirow{2}{*}{$22.8 \pm 1.1$} & 26.0 & 1.05 & 0.8661 \\
\hline & MAPP & & 28.0 & 3.40 & 0.9757 \\
\hline
\end{tabular}


a) Calculated from the intersection of the $\ln \sigma_{\text {Tred }}$ vs. $\varphi$ lines.

b) Determination coefficient indicating the goodness of the fit.

\subsection{Discussion, consequences}

Previous analysis proved that the interaction between PP and lignin is poor, but interfacial adhesion can be modified by coupling. The deformation and failure of the blends is determined by component properties, structure and interfacial adhesion. Debonding and particle fracture proved to be the two main local deformation processes at poor and good adhesion, respectively. The first results in small strength and deformability, while coupling increases tensile strength, but deformability remains small also in this case. The importance of local deformation processes is shown by the comparison of the critical stress of the dominating deformation process to the tensile strength of the blends. A characteristic stress $\left(\sigma_{\mathrm{AE}}\right)$ can be determined from the cumulative number of signal vs. deformation traces in the way shown in Fig. 5. Initiation deformation $\left(\varepsilon_{\mathrm{AE}}\right)$ is obtained by the extrapolation of the increasing, straight section of the correlation and initiation stress can be derived from that value. Tensile strength is plotted against initiation stress in Fig. 12. A close correlation is obtained between the two quantities indicating that the tensile strength of the blends is practically determined by local processes. As soon as any of these processes are initiated, the catastrophic failure of the blends occurs. The close grouping of points in the upper right corner of the plot also indicates that tensile strength is determined by the inherent strength of lignin particles which changes in a relatively narrow range. Increasing the deformability and strength of lignin particles might be a way to improve the properties of PP/lignin blends. 


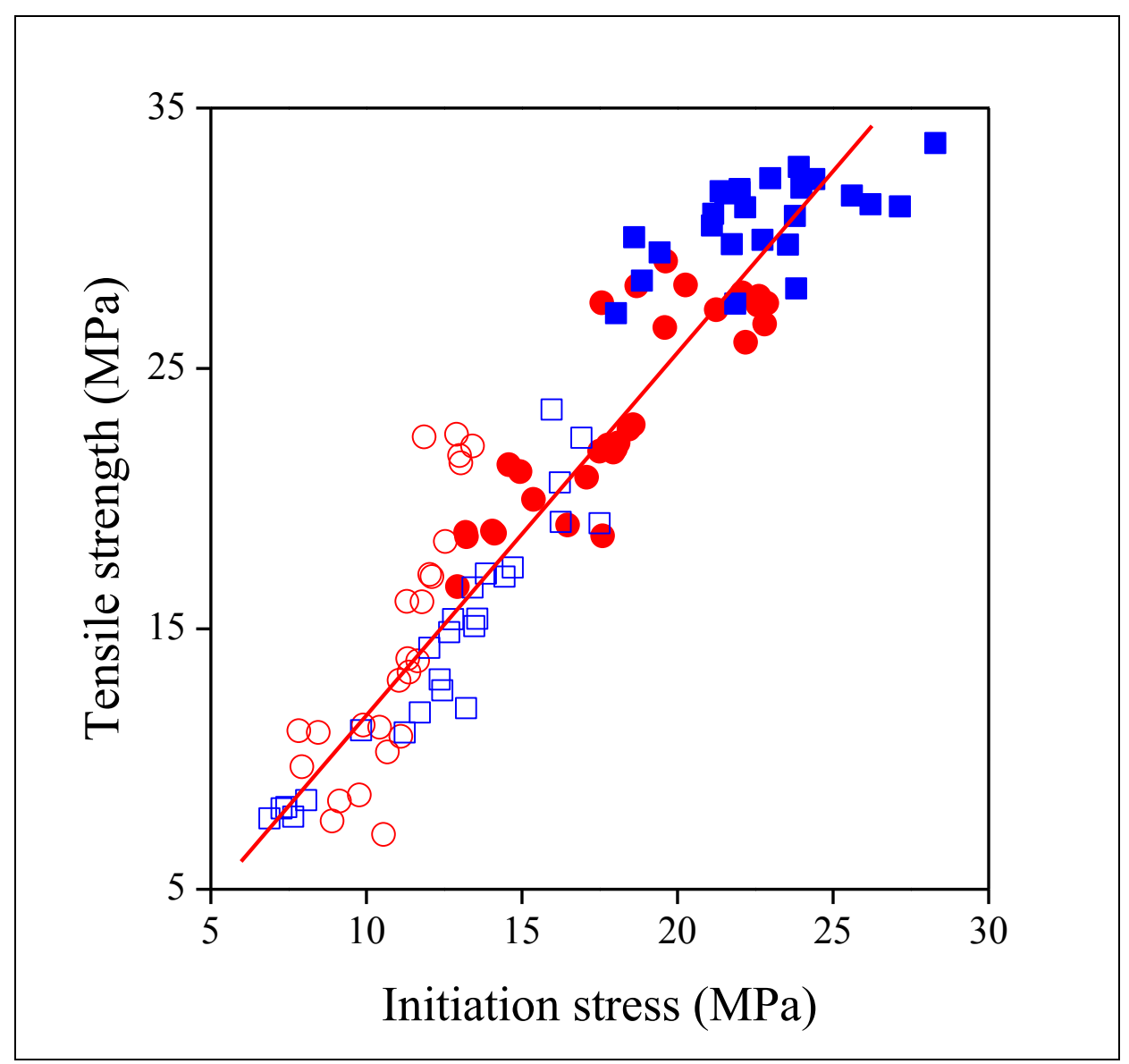

Figure 12. Correlation between the initiation stress $\left(\sigma_{\mathrm{AE}}\right)$ of the dominating deformation process determined by acoustic emission testing and the tensile strength of PP/lignin blends.

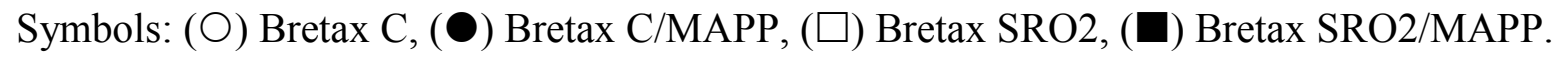




\section{Conclusions}

The analysis of results obtained by various measurements showed that the structure of PP/lignin blends form during processing by the breakup of large lignin particles which soften at the high temperature of processing. Practically all evidence indicates the development of weak interactions between PP and lignin; in fact the interactions among lignin molecules are much stronger and prevent any mixing of the two components. As a consequence, dispersed structure forms in the entire composition range studied, a co-continuous structure cannot develop at all, further confirming weak interactions and poor miscibility. Interfacial adhesion can be improved through the addition of a MAPP coupling agent. Depending on the strength of interfacial adhesion the blends fail either by debonding or the fracture of the lignin particles. Although coupling improves the stiffness and even more the tensile strength of PP/lignin blends, deformability is very small especially at larger lignin content representing the largest obstacle of practical application. Better dispersion, stronger interactions and modified lignin properties may lead to the improvement of blend properties.

\section{Acknowledgements}

The authors are indebted to Gábor Szabó and Péter Dénes for sample preparation, and to József Hári for the preparation of SEM micrographs. The research on heterogeneous polymer systems was financed by the National Scientific Research Fund of Hungary (OTKA Grant No. K 101124). One of the authors (KR) is grateful also to the János Bolyai Research Scholarship of the Hungarian Academy of Sciences. 


\section{References}

1. Sarkanen, K.V.; Ludwig, C.H. Lignins: Occurrence, Formation, Structure and Reactions; John Wiley \& Sons, Inc.: New York, 1971.

2. Doherty, W.O.S.; Mousavioun, P.; Fellows, C.M. Value-adding to Cellulosic Ethanol: Lignin Polymers. Ind. Crop. Prod. 2011, 33, 259-276.

3. Krotscheck, A.W.; Sixta, H. In Handbook of Pulp; Sixta, H., Ed.; Wiley-VCH: Weinheim, 2006; pp 967-996.

4. Plank, J. Applications of Biopolymers and Other Biotechnological Products in Building Materials. Appl. Microbiol. Biotechnol. 2004, 66, 1-9.

5. Winowiski, T.S.; Zajakowski, V.L. Animal Feed Incorporating Reactive Magnesium Oxide. US 6113974 A, 2000.

6. Buchholz, R.F.; Quinn, D.W. Particulate Fertilizer Dust Control. US 5360465 A, 1994.

7. Richter, S.J.; Brink, D.L.; Diddams, D.G.; Peter, O. Process for Making Vanillin. US 2434626 A, 1948.

8. Cisney, M.E.; Wethern, J.D. Making Dimethyl Sulfide from Pulp Mill Spent Liquors. US 2816832 A, 1957.

9. Gohen, D.W. Process of Making Methyl Mercaptan. US 2840614 A, 1958.

10. Chodák, I.; Brežný, R.; Rychlá, L. Blends of Polypropylene with Lignin: I. Influence of a Lignin Addition on Crosslinking and Thermooxidation Stability of Polypropylene. Chem. Pap. 1986, 40, 461-470.

11. Ciemniecki, S.L.; Glasser, W.G. Multiphase Materials with Lignin: 1. Blends of Hydroxypropyl Lignin with Poly(methyl methacrylate). Polymer 1988, 29, 1021-1029.

12. Ciemniecki, S.L.; Glasser, W.G. Multiphase Materials with Lignin: 2. Blends of 
Hydroxypropyl Lignin with Poly(vinyl alcohol). Polymer 1988, 29, 1030-1036.

13. Košíková, B.; Revajová, A.; Demianová, V. The effect of Adding Lignin on Modification of Surface Properties of Polypropylene. Eur. Polym. J. 1995, 31, 953-956.

14. Li, Y.; Mlynár, J.; Sarkanen, S. The First 85\% Kraft Lignin-Based Thermoplastics. J. Polym. Sci. Part B: Polym. Phys. 1997, 35, 1899-1910.

15. Feldman, D.; Banu, D. Contribution to the Study of Rigid PVC Polyblends with Different Lignins. J. Appl. Polym. Sci. 1997, 66, 1731-1744.

16. Nitz, H.; Semke, H.; Mülhaupt, R. Influence of Lignin Type on the Mechanical Properties of Lignin Based Compounds. Macromol. Mater. Eng. 2001, 286, 737-743.

17. Košiková, B.; Gregorová, A. Sulfur-Free Lignin as Reinforcing Component of StyreneButadiene Rubber. J. Appl. Polym. Sci. 2005, 97, 924-929.

18. Gregorová, A.; Košiková, B.; Staško, A. Radical Scavenging Capacity of Lignin and Its Effect on Processing Stabilization of Virgin and Recycled Polypropylene. J. Appl. Polym. Sci. 2007, $106,1626-1631$.

19. Košiková, B.; Gregorová, A.; Osvald, A.; Krajčovičová, J. Role of Lignin Filler in Stabilization of Natural Rubber-Based Composites. J. Appl. Polym. Sci. 2007, 103, 1226-1231.

20. Ago, M.; Jakes, J.E.; Johansson, L-S. Park, S.; Rojas, O.J. Interfacial Properties of LigninBased Electrospun Nanofibers and Films Reinforced with Cellulose Nanocrystals. ACS Appl. Mater. Inter. 2012, 4, 6849-6856.

21. Mousavioun, P.; Halley, P.J.; Doherty, W.O.S. Thermophysical Properties and Rheology of PHB/Lignin Blends. Ind. Crop. Prod. 2013, 50, 270-275.

22. Kaewtatip, K.; Thongmee, J. Effect of Kraft Lignin and Esterified Lignin on The Properties of Thermoplastic Starch. Mater. Design 2013, 49, 701-704. 
23. Wang, S-X.; Yang, L.; Stubbs, L.P.; Li, X.; He, C. Lignin-Derived Fused Electrospun Carbon Fibrous Mats as High Performance Anode Materials for Lithium Ion Batteries. ACS Appl. Mater. Inter. 2013, 5, 12275-12282.

24. Jiang, C.; He, H.; Yu, P.; Wang, D.K.; Zhou, L.; Jia, D.M. Plane-Interface-Induced LigninBased Nanosheets and Its Reinforcing Effect on Styrene-Butadiene Rubber. Express Polym. Lett. 2014, 8, 619-634.

25. Yu, P.; He, H.; Jiang, C.; Wang, D.; Jia, Y.; Zhou, L.; Jia, D.M. Reinforcing Styrene Butadiene Rubber with Lignin-Novolac Epoxy Resin Networks. Express Polym. Lett. 2015, 9, 36-48.

26. Gordobil, O.; Delucis, R.; Egüés, I.; Labidi, J. Kraft Lignin as Filler in PLA to Improve Ductility and Thermal Properties. Ind. Crop. Prod. 2015, 72, 46-53.

27. Pukánszky, B. In Polypropylene: Structure, Blends and Composites; Karger-Kocsis, J., Ed.; Chapman and Hall: London, 1995; Volume 3, pp 1-70.

28. Pukánszky, B.; Tüdős, F.; Kalló, A.; Bodor, G. Multiple Morphology in Polypropylene/Ethylenepropylene-diene Terpolymer Blends. Polymer 1989, 30, 1399-1406.

29. Menyhárd, A.; Suba, P.; László, Zs.; Fekete, H.M.; Mester, Á.O.; Horváth, Zs.; Vörös, Gy.; Varga, J.; Móczó, J. Direct Correlation between Modulus and the Crystalline Structure in Isotactic Polypropylene. Express Polym. Lett. 2015, 9, 308-320.

30. Horváth, Zs.; Menyhárd, A.; Doshev, P.; Gahleitner, M.; Vörös, Gy.; Varga, J.; Pukánszky, B. Effect of the Molecular Structure of the Polymer and Nucleation on the Optical Properties of Polypropylene Homo- and Copolymers. ACS Appl. Mater. Inter. 2014, 6, 7456-7463.

31. Olabisi, O.; Robeson, L.M.; Shaw, M.T. Polymer-Polymer Miscibility; Academic Press: New York, 1979.

32. Bucknall, C.B. Toughened plastics; Applied Science Publishers: London, 1977. 
33. Deanin, R.D.; Driscoll, S.B.; Cook, R.J.; Dubreuil, M.P.; Hellmuth, W.N.; Shaker, W.A. Lignin as a Filler in Commodity Thermoplastics. Soc. Plast. Eng. Tech. Pap. 1978, 24, 711.

34. Kadla, J.F.; Kubo, S. Lignin-Based Polymer Blends: Analysis of Intermolecular Interactions in Lignin-Synthetic Polymer Blends. Composites Part A 2004, 35, 395-400.

35. Pouteau, C.; Baumberger, S.; Cathala, B.; Dole, P. Lignin-Polymer Blends: Evaluation of Compatibility by Image Analysis. C. R. Biologies 2004, 327, 935-943.

36. Košiková, B.; Demianová, V.; Kačuráková, M. Sulfur-Free Lignins as Composites of Polypropylene Films. J. Appl. Polym. Sci. 1993, 47, 1065-1073.

37. Jeong, H.; Park, J.; Kim, S.; Lee, J.; Cho, J.W. Use of Acetylated Softwood Kraft Lignin as Filler in Synthetic Polymers. Fiber. Polym. 2012, 13, 1310-1318.

38. Kubat, J.; Stroemvall, H.E. Properties of Injection Molded Lignin-Filled Polyethylene and Polystyrene. Plast. Rubber Process. Appl. 1983, 3, 111.

39. Glasser, W.G.; Knudsen, J.S.; Chang, C.-S. Multiphase Materials with Lignin. III. Polyblends with Ethylene-Vinyl Acetate Copolymers. J. Wood. Chem. Technol. 1988, 8, 221-234.

40. Ciemniecki, S.L.; Glasser, W.G. Polymer Blends with Hydroxypropyl Lignin. ACS Symp. Ser. 1989, 397, 452-463.

41. Sánchez, C.G.; Expósito Alvarez, L.A. Micromechanics of Lignin/Polypropylene Composites Suitable for Industrial Applications. Angew. Makromol. Chem. 1999, 272, 65-70.

42. Pucciariello, R.; Villani, V.; Bonini, C.; D'Auria, M.; Vetere, T. Physical Properties of Straw Lignin-Based Polymer Blends. Polymer 2004, 45, 4159-4169.

43. Luo, F.; Ning, N.; Chen, L.; Su, R.; Cao, J.; Zhang, Q.; Fu, Q. Effects of Compatibilizers on the Mechanical Properties of Low Density Polyethylene/Lignin Blends. Chin. J. Polym. Sci. 2009, 27, 833-842. 
44. Sailaja, R.R.N.; Deepthi, M.V. Mechanical and Thermal Properties of Compatibilized Composites of Polyethylene and Esterified Lignin. Mater. Design 2010, 31, 4369-4379.

45. Maldhure, A.V.; Ekhe, J.D.; Deenadayalan, E. Mechanical Properties of Polypropylene Blended with Esterified and Alkylated Lignin. J. Appl. Polym. Sci. 2012, 125, 1701-1712.

46. Kharade, A.Y.; Kale, D.D. Lignin-Filled Polyolefins. J. Appl. Polym. Sci. 1999, 72, 13211326.

47. Alexy, P.; Košiková, B.; Podstránska, G. The Effect of Blending Lignin with Polyethylene and Polypropylene on Physical Properties. Polymer 2000, 41, 4901-4908.

48. Cazacu, G.; Pascu, M.C.; Profire, L.; Kowarski, A.I.; Mihaes, M.; Vasile, C. Lignin Role in a Complex Polyolefin Blend. Ind. Crop. Prod. 2004, 20, 261-273.

49. Cazacu, G.; Mihaies, M.; Pascu, M.C.; Profire, L.; Kowarskik, A.L.; Vasile, C. Polyolefin/Lignosulfonate Blends, 9 - Functionalized Polyolefin/Lignin Blends. Macromol. Mater. Eng. 2004, 289, 880-889.

50. Chen, F.; Dai, H.; Dong, X.; Yang, J.; Zhong, M. Physical Properties of Lignin-Based Polypropylene Blends. Polym. Compos. 2011, 32, 1019-1025.

51. Vasile, C.; Iwanczuk, A.; Frackoviak, S.; Cazacu, G.; Constantinescu, G.; Kozlowski, M. Modified Lignin/Polyethylene Blends. Cellul. Chem. Technol. 2006, 40, 345.

52. Casenave, S.; Aït-Kadi, A.; Riedl, B. Mechanical Behaviour of Highly Filled Lignin/Polyethylene Composites Made by Catalytic Grafting. Can. J. Chem. Eng. 1996, 74, $308-315$.

53. Alexy, P.; Košiková, B.; Crkonová, G.; Gregorová, A.; Martiš, P. Modification of LigninPolyethylene Blends with High Lignin Content Using Ethylene-Vinylacetate Copolymer as Modifier. J. Appl. Polym. Sci. 2004, 94, 1855-1860. 
54. Myrvold, B.O. The Hansen Solubility Parameters of Some Lignosulfonates. World Acad. Sci. Eng. Technol. Trans. Energy Power Eng. 2014, 1, 261.

55. Krause, S. In Polymer Blends; Paul, D.R., Newman S., Eds.; Academic Press: New York, 1978; Volume 1, pp 16-106.

56. Renner, K.; Yang, M.S.; Móczó, J.; Choi, H.J.; Pukánszky, B. Analysis of the Debonding Process in Polypropylene Model Composites. Eur. Polym. J. 2005, 41, 2520-2529.

57. Dányádi, L.; Renner, K.; Szabó, Z.; Nagy, G.; Móczó, J.; Pukánszky, B. Wood Flour Filled PP Composites: Adhesion, Deformation, Failure. Polym. Adv. Technol. 2006, 17, 967-974.

58. Sudár, A.; Burgstaller, C.; Renner, K.; Móczó, J.; Pukánszky, B. Wood Fiber Reinforced Multicomponent, Multiphase PP Composites: Structure, Properties, Failure Mechanism. Compos. Sci. Technol. 2014, 103, 106-112.

59. Faludi, G.; Link, Z.; Renner, K.; Móczó, J.; Pukánszky, B. Factors Determining the Performance of Thermoplastic Polymer/Wood Composites; The Limiting Role of Fiber Fracture. Mater. Design 2014, 61, 203-210.

60. Pukánszky, B. Influence of Interface Interaction on the Ultimate Tensile Properties of Polymer Composites. Composites 1990, 21, 255-262.

61. Fekete, E.; Pukánszky, B.; Peredy, Z. Mutual Correlations between Parameters Characterizing the Miscibility, Structure and Mechanical Properties of Polymer Blends. Angew. Makromol. Chem. 1992, 199, 87-101.

62. Liu, X.H.; Wu, Q.J. PP/Clay Nanocomposites Prepared by Grafting-Melt Intercalation. Polymer 2001, 42, 10013-10019.

63. Százdi, L.; Pukánszky Jr, B.; Vancso, G.J.; Pukánszky, B. Quantitative Estimation of the Reinforcing Effect of Layered Silicates in PP Nanocomposites. Polymer 2006, 47, 4638-4648. 